\title{
Llibres rebuts
}

IOdAR, Pere; Madariaga, Rafael; Martori, Joan Carles; MendozA, Rocío (1994). La confección en Santa Coloma de Gramenet. Estudio de las empresas: producción y calidad en 1993. Barcelona: Grameimpuls, 308 p.

OLiN Wright, Erik (1994). Clases. Madrid: Siglo XXI, 375 p.

KLAUS VON BeYME (1994). Teoría politica del siglo XX. De la modernidad a la posmodernidad. Madrid: Alianza, $381 \mathrm{p}$.

SARRIES SANZ, Luis (1994). Los nuevos modelos de organización empresarial y la recualificación de los puestos de trabajo en la industria navarra. Análisis del sector automoción y electrodomésticos. Pamplona: Gobierno de Navarra, $131 \mathrm{p}$.

\section{Revistes}

Perspectiva social, núm. 34 (1994). Monograffic sobre "La presó avui: els problemes que planteja».

Theoria. Revista de teoria, historia y fundamentos de la ciencia, núm. 21 (septiembre 1994). Universidad del País Vasco.

Desarrollo económico. Revista de Ciencias Sociales, núm. 134 (julio-septiembre 1994). Buenos Aires: Instituto de Desarrollo Económico y Social.

Frontera norte, especial núm. 1, vol. 6 (1994). "La pobreza: aspectos teóricos, metodologicos y empiricos".

Frontera norte, núm. 11, vol. 6 (enero-junio 1994).

Revista Paraguaya de Sociología, núm. 89 (enero-abril 1994). «Estado, democracia y clase social'.

Sociedad y utopia, núm. 4 (1994). dossier sobre "La sociedad del bienestar". American Studies, núm. 2, vol. 35 (Fall 1994).

Sex Roles, núm. 3/4, vol. 31 (august 1994).

Sex Roles, núm. 6/7, vol. 31 (october 1994).

Revue française de sociologie, núm. 4, vol. xxxv (octobre-décembre1994). "Monde étudiant et monde scolaire".

Antropología, núm. 7, (marzo 1994). "Representación política y contexto local». Il Progetto, núm. 83-84, (settembre-dicembre 1994), "La scelta partecipativa». 
Panorama centroamericano, núm. 99, (noviembre 1994).

El correo fronterizo, núm. 4, (septiembre-octubre 1994).

Tendencias, núm. 36, (diciembre 1994 - enero 1995).

Fomento del Trabajo. Horizonte empresarial, núm. 2052 (octubre 1994). Barcelona: Fomento del Trabajo Nacional.

Fomento del Trabajo. Horizonte empresarial. «La responsabilidad civil», núm. 2053 (noviembre 1994). Barcelona: Fomento del Trabajo Nacional.

Fomento del Trabajo. Horizonte empresarial. "La ley de arrendamientos urbanos", núm. 2054 (diciembre 1994). Barcelona: Fomento del Trabajo Nacional.

Fomento del Trabajo. Horizonte empresarial. "Elecciones a Fomento del Trabajo", núm. 2055 (enero 1995). Barcelona: Fomento del Trabajo Nacional.

\section{Working Papers}

Institut de Ciències Politiques $i$ Socials:

Núm. 92. "Political Culture and Political Communication", by David L. Paletz \&. Daniel Lipinski.

Núm. 93. "La crise de la politique en France", par Janine Mossuz-Lavau.

Núm. 94. "El sistema político y la política exterior: el ciclo formal", por Pere Vilanova.

Núm. 95. "Giurisdizione e politica antiche domande sull'onda del caso italiano", di Massimo Morisi.

Núm. 96. "El derecho a la intimidad, el derecho a la autodeterminación informativa y la L.O. 5/1992, de 29 de octubre, de regulación del tratamiento automatizado de daros personales", por Ana Rosa González Murúa.

Núm. 97. "Les nationalismes français», par Michel Winock.

Núm. 98. "A Qualitative Approach to Electoral Abstention", by Mª Rosa Virós.

Núrn. 99: "Green Parties under Comparative Perspective», by Ferdinand MüllerRommel.

Núm. 100: “Abstenir-se és una altra manera de participar», per Isidre Molas.

Fundacio Rafael Campalans:

Núm. 64. «Etica i política» per Joan Manuel del Pozo.

Núm. 65: «La cooperación española para el desarrollo», por José Luis Dicenta. 